\title{
Enhanced Electromagnetic Wave Absorption Properties of Poly(3,4-ethylenedioxythiophene) Nanofiber-Decorated Graphene Sheets by Non-covalent Interactions
}

\author{
Xiang Zhang ${ }^{1} \cdot$ Ying Huang ${ }^{1}$ Panbo Liu ${ }^{1}$
}

Received: 25 August 2015/ Accepted: 16 September 2015/Published online: 13 October 2015

(C) The Author(s) 2015. This article is published with open access at Springerlink.com

\begin{abstract}
Graphene sheets (GNs) have high conductivity, but they exhibit weak electromagnetic (EM) wave absorption performance. Here, poly (3,4-ethylenedioxythiophene) (PEDOT) nanofibers were decorated on the surface of GNs in which the residual defects and groups act as the active sites and therefore are beneficial for the deposition of PEDOT nanofibers. The SEM images display that PEDOT nanofibers are successfully decorated on the surface of GNs through in situ polymerization. The diameter of the PEDOT nanofibers were ranged from 15 to $50 \mathrm{~nm}$ with hundreds of nanometers in length. The EM wave absorption properties of graphene, PEDOT, and GNs-PEDOT were also investigated. Compared to pure graphene and PEDOT, the EM wave absorption properties of GNs-PEDOT improved significantly. The maximum value of $R_{\mathrm{L}}$ was up to $-48.1 \mathrm{~dB}$ at $10.5 \mathrm{GHz}$ with a thickness of only $2 \mathrm{~mm}$. Meanwhile, the absorption bandwidth of $R_{\mathrm{L}}$ values below $-10 \mathrm{~dB}$ was $9.4 \mathrm{GHz}(5.8-12.3,12.9-15.8 \mathrm{GHz})$ in the thickness of $1.5-3 \mathrm{~mm}$. The enhancement is attributed to the modification of PEDOT and the unique structure of nanofibers. On one hand, the deposition of PEDOT nanofibers on the surface of GNs decreases the conductivity of graphene, and makes impedance match better. On the other hand, the unique structure of PEDOT nanofibers results in relatively large specific surfaces areas, providing more active sites for reflection and scattering of EM waves. Therefore, our findings demonstrate that the deposition of conducting polymers on GNs by non-covalent bond is an efficient way to fabricate strong EM wave absorbers.
\end{abstract}

Keywords Graphene $\cdot$ PEDOT $\cdot$ Nanofibers $\cdot$ Electromagnetic wave absorption

\section{Introduction}

In recent decades, electromagnetic interference (EMI) problem has emerged due to the increasing use of electronic devices and communication facilities in most areas, leading to complex electromagnetic environment. An effective way to solve the problem is developing EM wave absorbing materials, which can absorb EM wave effectively and convert EM energy into thermal energy or dissipate the EM waves by

Ying Huang

yingh@nwpu.edu.cn

1 Key Laboratory of Space Applied Physics and Chemistry, Ministry of Education, School of Science, Northwestern Polytechnical University, Xi' an 710129 ,

People's Republic of China interference. Therefore, considerable efforts have been made to develop strong, lightweight, and broadband absorbing materials [1-3]. Typically, traditional materials such as ferrite, graphite, and carbon nanotubes (CNTs) have been used for EM wave absorption materials due to their high conductivity and good dielectric properties [4-6]. However, these materials cannot reach the standards of ideal EM wave absorption materials. The high density, corrosion susceptibility, and narrow bandwidth of absorption frequency limit ferrite's applications [7-9]. Similarly, graphite has poor dispensability and relatively low absorbing abilities. Likewise, CNTs are economically non-viable, difficult to produce at bulk scale and require purification, auxiliary treatment, and functionalization steps $[10,11]$. Therefore, designing and fabricating new type of EM wave absorption materials are highly demanded.

Graphene, a novel two-dimensional carbon material, has triggered enormous interest due to its fascinating electrical 
properties [12, 13]. Graphene possesses not only a stable structure but also high-specific surface area and excellent electronic conductivity. These properties make graphene or graphene-based materials very promising as a new type of strong and lightweight EM wave absorption materials [14]. However, the study finds out that the maximum reflection loss of sole GNs is only $-6.9 \mathrm{~dB}$, because its good electric conductivity becomes a disadvantageous factor according to the impedance match mechanism [2]. Nevertheless, previous research demonstrates that the residual defects and groups in GNs can act as the active sites, which may be beneficial for grafting (combining) conducting polymers by non-covalent bond, and improving the EM wave absorption properties of GNs. Over the last four decades, conducting polymer-based composites have attracted much attention, because of facile synthesis, light weight, low cost, easy processing ability as well as tunable dielectric and magnetic attributes [15-17]. Among conducting polymers, poly (3,4-ethylenedioxythiophene) (PEDOT) has been considered as a promising candidate for EM wave absorbers due to its tunable dielectric and magnetic attributes and excellent environmental stability [18-20]. Yu et al. synthesized graphene/polyaniline (PANI) nanorod arrays and the sample exhibited a maximum absorption of $-45.1 \mathrm{~dB}$ with a thickness of $2.5 \mathrm{~mm}$ [21]. In our previous work, we synthesized graphene-PANI film, and the results showed the maximum reflection loss was $-41.4 \mathrm{~dB}$ with a thickness of $2.0 \mathrm{~mm}$ [22]. Ni et al. fabricated PEDOT microspheres with a layer thickness of $2 \mathrm{~mm}$, and the maximum absorption is $-25 \mathrm{~dB}$ at $15.9 \mathrm{GHz}$ [20]. Even higher reflection loss of $-30 \mathrm{~dB}$ at $9.5 \mathrm{GHz}$ is observed by synthesizing the $\mathrm{Fe}_{3} \mathrm{O}_{4}$ PEDOT microspheres with EDOT/ $\mathrm{Fe}_{3} \mathrm{O}_{4}$ ratio of 20 [23]. To the best of our knowledge, the EM wave absorption properties of GNs-PEDOT nanofibers have never been reported.

In this paper, PEDOT nanofibers were directly grown on the surface of GNs by non-covalent interactions through in situ polymerization. The maximum reflection loss of the nanocomposites reaches $-48.1 \mathrm{~dB}$, and the absorption bandwidth exceeding $-10 \mathrm{~dB}$ is $3.1 \mathrm{GHz}$ with a thickness of only $2 \mathrm{~mm}$. Meanwhile, the absorption bandwidth corresponding to reflection loss below $-10 \mathrm{~dB}$ is $9.4 \mathrm{GHz}(5.8-12.3$, $12.9-15.8 \mathrm{GHz}$ ) in the range of $1.5-3 \mathrm{~mm}$. Moreover, the addition amount of the nanocomposites into the paraffin matrix is only $25 \mathrm{wt} \%$. Thus, GNs-PEDOT nanofibers are very promising as lightweight EM wave-absorbing materials.

\section{Experimental}

\subsection{Preparation}

Graphene oxide (GO) was prepared by Hummers method [24]. The nanocomposites were synthesized as follows:
Firstly, 0.2 g GO was dispersed in $200 \mathrm{~mL}$ deionized water and ultrasonicated for $1 \mathrm{~h}$, then $0.1 \mathrm{~mL}$ hydrazine was added and heated at $90{ }^{\circ} \mathrm{C}$ for $24 \mathrm{~h}$. Secondly, the obtained GNs were dissolved in deionized water by sonication treatment, afterward, $0.2 \mathrm{~mL}$ 3,4-ethylenedioxythiophene monomers dispersed in ethanol and $2 \mathrm{~mL} \mathrm{H}_{2} \mathrm{SO}_{4}$ were added. Then, $\left(\mathrm{NH}_{4}\right)_{2} \mathrm{~S}_{2} \mathrm{O}_{8}$, the oxidation, was added in the above solution. Thirdly, the mixture was cooled down to $0{ }^{\circ} \mathrm{C}$ and stirred for $24 \mathrm{~h}$. The obtained product was washed with water until pH 7 and dried at $60^{\circ} \mathrm{C}$ for $12 \mathrm{~h}$.

\subsection{Characterization}

The molecular structures of GNs-PEDOT nanofibers were observed on Fourier transform infrared spetctroscopy (FTIR, NICOLET iS10). Raman spectroscopy were characterized by Renishaw in Via Raman Microscope. The chemical states were investigated by X-ray photoelectron spectroscopy (XPS, PHI $5300 \times$ ). The morphology were characterized by fieldemission scanning electron microscope (FESEM, Quanta 600FEG) and transmission electron microscope (TEM, Tecnai $\mathrm{F} 30 \mathrm{G}^{2}$ ). The electromagnetic parameters of samples were measured in a HP8753D vector network analyzer at the frequency range of 2-18 GHz. The samples were prepared by mixing $25 \mathrm{wt} \%$ of the nanocomposites with a paraffin matrix uniformly. The mixture was then pressed into toroidal-shaped samples (H $2.0 \mathrm{~mm}, \varphi_{\text {out }} 7.0 \mathrm{~mm}, \varphi_{\text {in }} 3.0 \mathrm{~mm}$ ). The input power level of the incident microwave is $-5.0 \mathrm{dBm}$.

\section{Results and Discussion}

The formation mechanism of GNs-PEDOT is schematically depicted in Fig. 1a. GO was firstly reduced to GNs by hydrazine. Then, 3,4-ethylenedioxythiophene (EDOT) monomers were grafted on the active sites (residual defects and groups in GNs) by the electrostatic attraction. With the addition of $\mathrm{H}_{2} \mathrm{SO}_{4}$ and $\left(\mathrm{NH}_{4}\right)_{2} \mathrm{~S}_{2} \mathrm{O}_{8}$, EDOT monomers began to polymerize; thus, PEDOT nanofibers were formed. Figure $1 \mathrm{~b}$ shows the FTIR spectra of GNs-PEDOT. The characteristic peaks at 1515 and $1334 \mathrm{~cm}^{-1}$ are attributed to the $\mathrm{C}=\mathrm{C} / \mathrm{C}-\mathrm{C}$ stretching vibrations of the thiophene rings. The peaks at 1196,1141 , and $1081 \mathrm{~cm}^{-1}$ are ascribed to the $\mathrm{C}-$ O-C stretching, and the bands at 980, 840, and $692 \mathrm{~cm}^{-1}$ are ascribed to the $\mathrm{C}-\mathrm{S}$ bond in the thiophene rings, respectively. The results indicate that PEDOT is successfully grafted on the surface of GNs [25]. Figure 1c shows the Raman spectra of GO and GNs-PEDOT. For GO, the Raman spectrum is associated with a typical D band at $1350 \mathrm{~cm}^{-1}$ and a $\mathrm{G}$ band at $1590 \mathrm{~cm}^{-1}$. For GNs-PEDOT, apart from the D and $G$ bands, the bands at 1434 and $1515 \mathrm{~cm}^{-1}$ are attributed to $\mathrm{C}=\mathrm{C}$ stretching, whereas the bands at 575 and $989 \mathrm{~cm}^{-1}$ are assigned to oxyethylene ring deformation, and the band at 

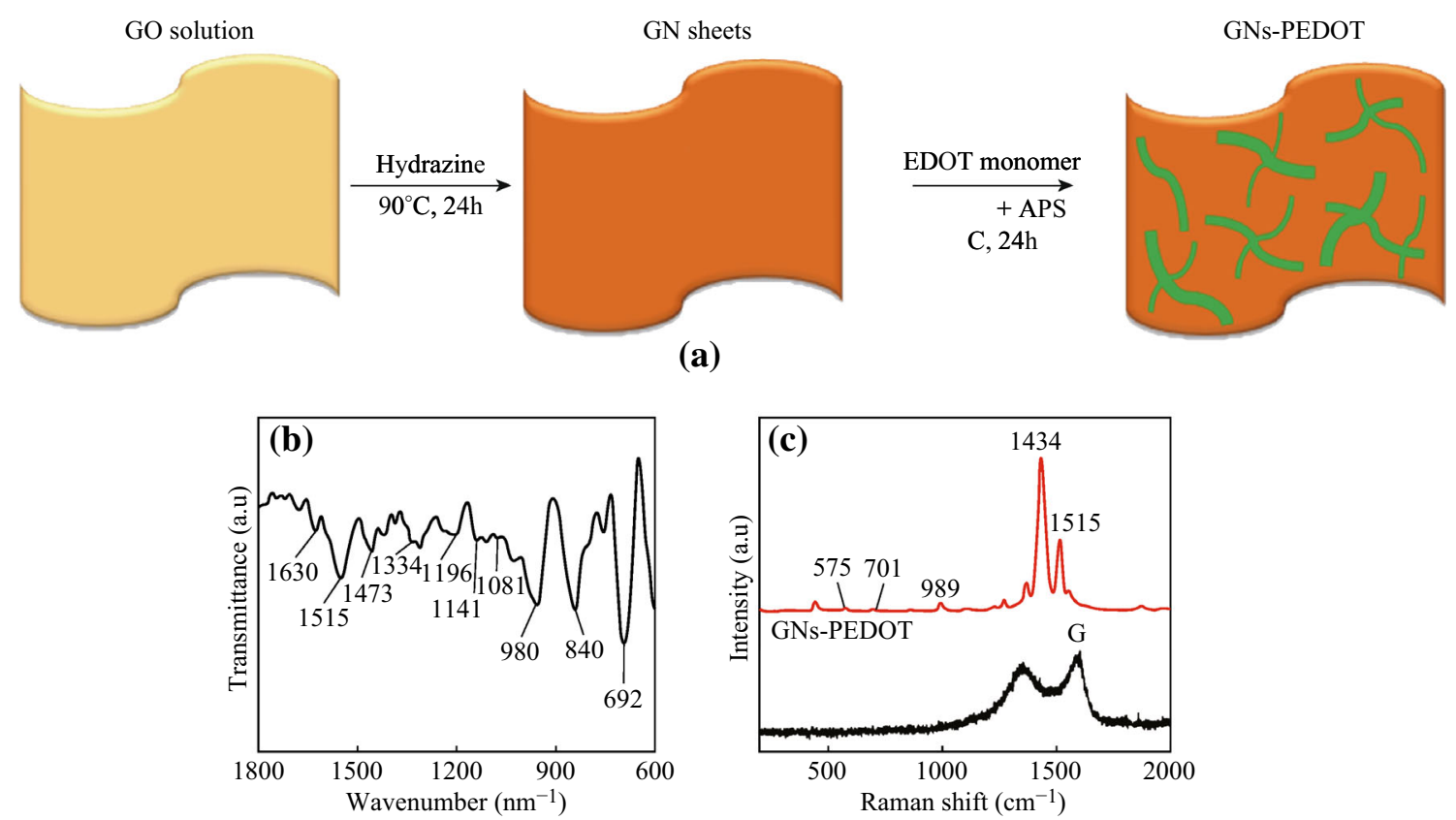

(a)

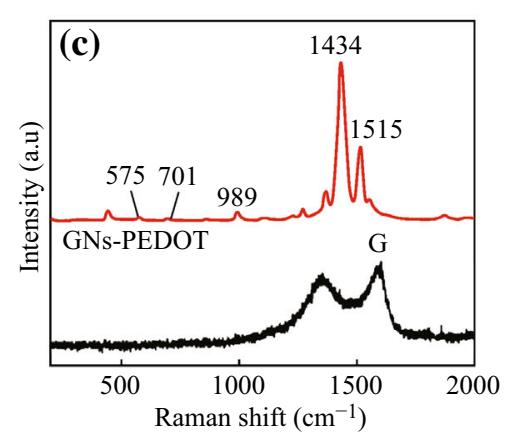

Fig. 1 a Schematic illustration of GNs-PEDOT. b FTIR spectra of GNs-PEDOT. c Raman spectra of GO and GNs-PEDOT

$701 \mathrm{~cm}^{-1}$ is related to symmetric C-S-C deformation, suggesting the formation of PEDOT [26]. In addition, the D and $G$ bands in GNs-PEDOT exhibit a blue or red shift compared with GO due to the strong interactions between GNs and PEDOT.

The morphology of the samples are shown in Fig. 2. In Fig. 2a, GNs exhibit typical transparent and rippled silk morphology. The HRTEM image of GNs signifies that GNs appear flat except for some wrinkles at the edge of it. The FESEM images in Fig. 2c, d show that GNs look like crumpled and curved attributing to the PEDOT nanofibers coated on the surface. Figure $2 \mathrm{e}$ displays the TEM image of GNs-PEDOT. It can be clearly seen that the surface of GNs is homogeneously covered with PEDOT nanofibers, and the PEDOT nanofibers distribute on the surface of GNs as indicated by the red arrows. Meanwhile, no free PEDOT nanofibers or naked GNs were observed, indicating that the nucleation and growth of PEDOT nanofibers only occur on the surface of GNs. Figure $2 \mathrm{f}$ shows the enlarged images of GNs-PEDOT. It can be clearly observed that the diameter of the PEDOT nanofibers ranges from 15 to $50 \mathrm{~nm}$ with hundreds of nanometers in length, which is different from previous report [16]. The special morphology may be favorable for the enhancement of the charge transfer between GNs and PEDOT nanofibers.

XPS was used to verify the surface composition of GNsPEDOT and the results are presented in Fig. 3. The wide scan XPS spectrum in Fig. 3a indicates that the existence of $\mathrm{C}, \mathrm{O}, \mathrm{S}$ elements in the nanocomposites, and no other elemental signals were detected in the general XPS spectrum. Figure $3 \mathrm{~b}$ shows the $\mathrm{C} 1 \mathrm{~s}$ spectra of GNs-PEDOT which is deconvoluted into five different peaks. The peaks centered at 284.6, 286.4, 287.8, and $289.3 \mathrm{eV}$ may be, respectively, attributed to $\mathrm{C}-\mathrm{C} / \mathrm{C}=\mathrm{C}, \mathrm{C}-\mathrm{O}$ or alkoxy, $\mathrm{C}=\mathrm{O}$, and $\mathrm{O}-\mathrm{C}=\mathrm{O}$ groups. In addition, the new peak centered at $285.3 \mathrm{eV}$ is for the $\mathrm{C}-\mathrm{S}$ group [27]. The $\mathrm{S} 2 p$ XPS spectra (see Fig. 3c) show the presence of sulfur spin-split doublet at around $164.0 \mathrm{eV}\left(\mathrm{S} \mathrm{2} p_{3 / 2}\right)$ and $165.1 \mathrm{eV}\left(\mathrm{S} 2 p_{1 / 2}\right)$ with an energy splitting of $1.1 \mathrm{eV}$, suggesting the formation of doped PEDOT.

To understand the EM wave absorption mechanisms, the real part $\left(\varepsilon^{\prime}\right)$ and imaginary part $\left(\varepsilon^{\prime \prime}\right)$ of the relative complex permittivity, as well as the real part $\left(\mu^{\prime}\right)$ and imaginary part $\left(\mu^{\prime \prime}\right)$ of the relative complex permeability of GNs-PEDOT were investigated. In Fig. $4 \mathrm{a}$, it can be seen that the $\varepsilon^{\prime}$ values varied from 17.5 to 10.8 , and the $\varepsilon^{\prime \prime}$ values decrease from 7.3 to 3.6 with several fluctuations in the frequency range of $2-18 \mathrm{GHz}$. In Fig. 4b, it reveals that the $\mu^{\prime}$ values are in the range of $0.9-1.1$ and the $\mu^{\prime \prime}$ values are less than 0.2 over $2-18 \mathrm{GHz}$. The dielectric loss tangent $\left(\tan \delta_{\varepsilon}=\right.$ $\left.\varepsilon^{\prime \prime} / \varepsilon^{\prime}\right)$ and magnetic loss tangent $\left(\tan \delta_{\mu}=\mu^{\prime \prime} / \mu^{\prime}\right)$ are shown in Fig. 4c. It can be noted that the $\tan \delta_{\varepsilon}$ values are higher than $\tan \delta_{\mu}$ in the range of $2-18 \mathrm{GHz}$, suggesting that GNsPEDOT mainly depends on the dielectric loss.

To clarify the EM absorption properties, the reflection losses $\left(R_{\mathrm{L}}\right)$ were calculated according to formula (1) and (2),

$R_{L}(\mathrm{~dB})=20 \log \left|\frac{Z_{\text {in }}-1}{Z_{\text {in }}+1}\right|$,
$Z_{\text {in }}=\sqrt{\mu_{r} / \varepsilon_{r}} \tanh \left[j(2 \pi f d / c) \sqrt{\varepsilon_{\mathrm{r}} \mu_{\mathrm{r}}}\right]$, 

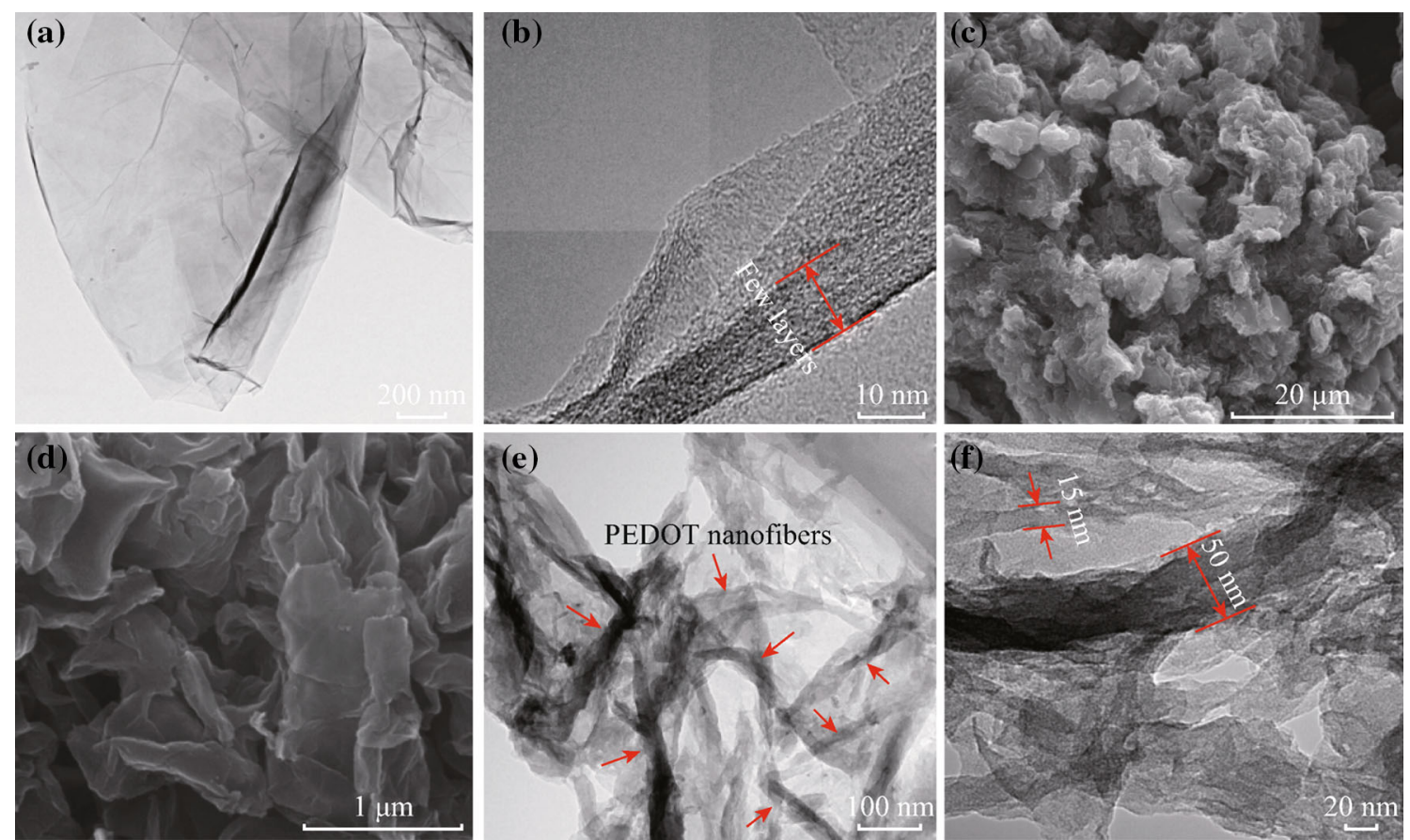

Fig. 2 a, b TEM images of GNs. c, d FESEM images of GNs-PEDOT. e, $\mathbf{f}$ TEM images of GNs-PEDOT
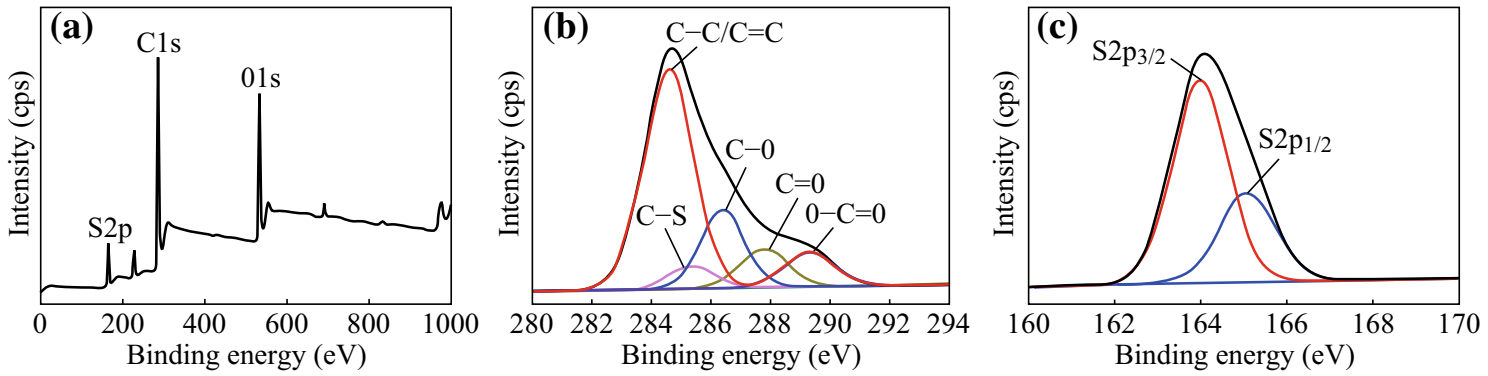

Fig. 3 a XPS spectrum, b C $1 s$ and c S $2 p$ spectra of GNs-PEDOT

where $Z_{\text {in }}$ is the input impedance of the absorber, $c$ the velocity of electromagnetic waves in free space, $f$ the frequency, and $d$ the layer thickness.

In Fig. 4d and e, one can clearly see that pure GN exhibits poor EM wave absorption properties in the range of $2-4 \mathrm{~mm}$, and the maximum $R_{\mathrm{L}}$ is only $-8.9 \mathrm{~dB}$ at 9.5 GHz. Similarly, pure PEDOT has weak attenuation to EM wave, and the maximum $R_{\mathrm{L}}$ is only $-14.5 \mathrm{~dB}$ at $7 \mathrm{GHz}$. After coating PEDOT nanofibers on the surface of GNs, the GNs-PEDOT nanofibers show better EM wave absorbing properties in terms of both maximum $R_{\mathrm{L}}$ value and absorption bandwidth. The maximum $R_{\mathrm{L}}$ is up to $-48.1 \mathrm{~dB}$ at $10.5 \mathrm{GHz}$, and the absorption bandwidth corresponding to the $R_{\mathrm{L}}$ values below $-10 \mathrm{~dB}$ is $3.1 \mathrm{GHz}$ (from 9.2 to $12.3 \mathrm{GHz}$ ) with a thickness of $2 \mathrm{~mm}$. Furthermore, it is obvious that the maximum $R_{\mathrm{L}}$ values are less than $-17 \mathrm{~dB}$ with the thickness of $1.5-3 \mathrm{~mm}$. The results also demonstrate that GNs-PEDOT nanofibers present better EM wave absorption properties than PEDOT microspheres [20], flake-like PANIs [28] and graphene/ PANI nanorods [21]. The enhancement is attributed to the modification of PEDOT nanofibers and the unique structure. On one hand, the deposition of PEDOT nanofibers on the surface of GNs decreases the conductivity of graphene, and makes impedance match better. On the other hand, the unique structure of PEDOT nanofibers results in relatively large specific surfaces areas, providing more active sites for reflection and scattering of EM waves. In addition, the reflection loss is sensitive to the heteroatom contents. Due to the heterogeneous media, there are more remarkable interfacial polarization and electron polarization which are helpful to improve the EM wave absorption performance. Furthermore, since PEDOT nanofibers with high conductivity grew on GNs by non-covalent bond, the charge 

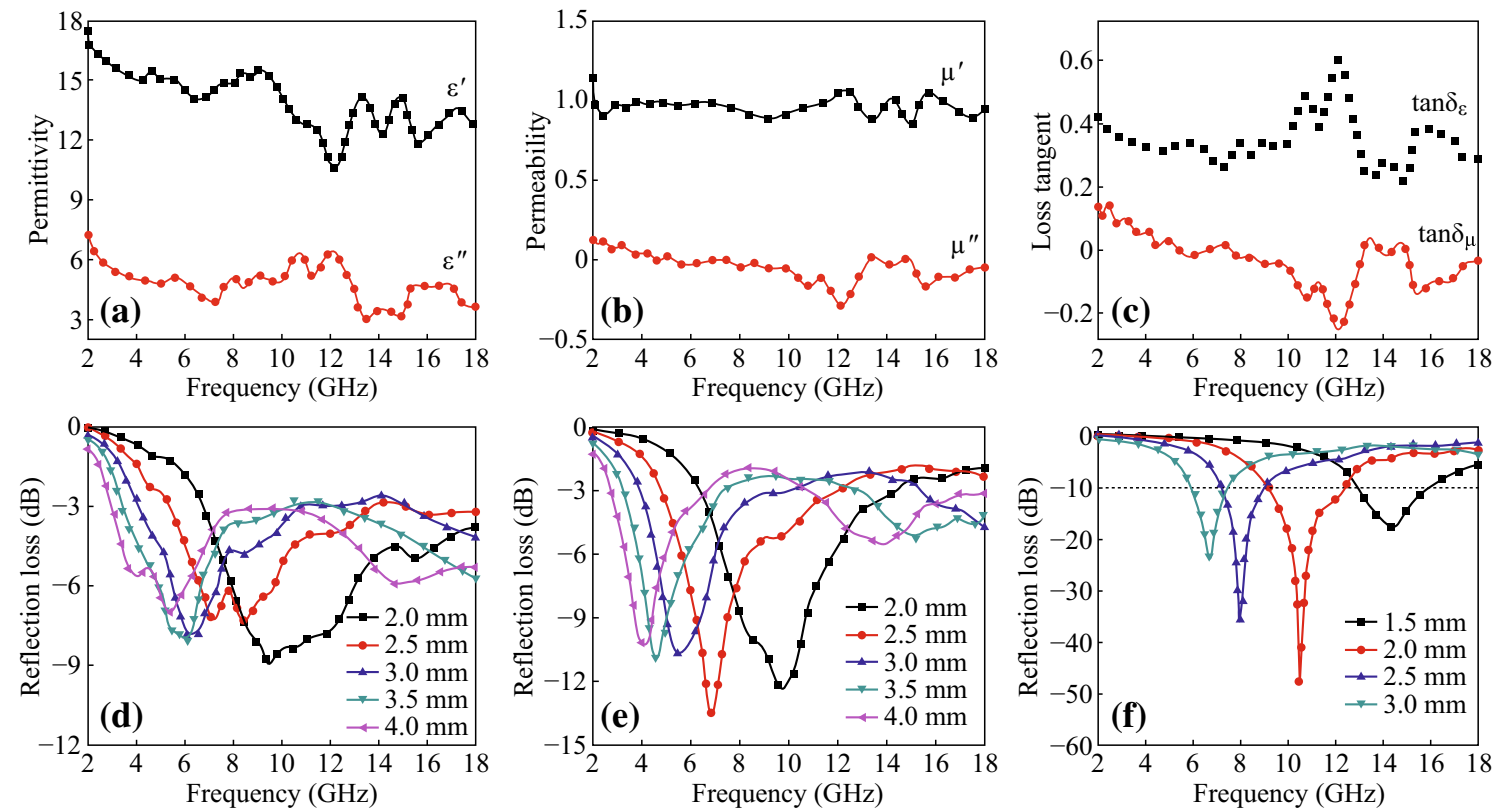

Fig. 4 The complex relative permittivity (a), permeability (b), and loss tangent (c) of GNs-PEDOT. Reflection loss curves of $\mathbf{d}$ GNs, e PEDOT and $\mathbf{f}$ GNs-PEDOT

transfer between GNs and PEDOT nanofibers contributes to the excellent EM wave absorption performance as well [21].

\section{Conclusions}

In summary, GNs-PEDOT nanofibers were synthesized via in situ polymerization method, and their EM wave absorption properties were investigated. TEM images indicate that PEDOT nanofibers were grafted on GNs, and the diameter ranged from 15 to $50 \mathrm{~nm}$. The results state that poor EM absorption properties of GNs can be significantly improved by deposition of PEDOT nanofibers on the surface of the GNs. The maximum reflection loss of GNs-PEDOT is $-48.1 \mathrm{~dB}$ with a thickness of only $2 \mathrm{~mm}$, and the absorption bandwidth corresponding to reflection loss below $-10 \mathrm{~dB}$ is $9.4 \mathrm{GHz}(5.8-12.3,12.9-15.8 \mathrm{GHz})$ in the thickness of $1.5-3 \mathrm{~mm}$. Thus, the deposition of dielectric nanostructures on the surface of the GNs is an efficient way to fabricate lightweight materials for strong and lightweight EM absorbers.

Open Access This article is distributed under the terms of the Creative Commons Attribution 4.0 International License (http://crea tivecommons.org/licenses/by/4.0/), which permits unrestricted use, distribution, and reproduction in any medium, provided you give appropriate credit to the original author(s) and the source, provide a link to the Creative Commons license, and indicate if changes were made.

\section{References}

1. H.M. Kim, K. Kim, C.Y. Lee, J. Joo, S.J. Cho, H.S. Yoon, D.A. Pejakovic, J.W. Yoo, A.J. Epstein, Electrical conductivity and electromagnetic interference shielding of multiwalled carbon nanotube composites containing Fe catalyst. Appl. Phys. Lett. 84(4), 589-591 (2004). doi:10.1063/1.1641167

2. C. Wang, X.J. Han, P. Xu, X.L. Zhang, Y.C. Du, S.R. Hu, The electromagnetic property of chemically reduced graphene oxide and its application as microwave absorbing material. Appl. Phys. Lett. 98(7), 072906 (2011). doi:10.1063/1.3555436

3. Y. Zhang, Y. Huang, T.F. Zhang, H.C. Chang, P.S. Xiao, H.H. Chen, Z.Y. Huang, Y.S. Chen, Broadband and tunable highperformance microwave absorption of an ultralight and highly compressible graphene foam. Adv. Mater. 27(12), 2049-2053 (2015). doi:10.1002/adma.201405788

4. Y.L. Yang, M.C. Gupta, K.L. Dudley, R.W. Lawrence, Novel carbon nanotube-polystyrene foam composites for electromagnetic interference shielding. Adv. Mater. 17(16), 1999-2003 (2005). doi:10.1021/n1051375r

5. P. Saini, V. Choudhary, Enhanced electromagnetic interference shielding effectiveness of polyaniline functionalized carbon nanotubes filled polystyrene composites. J. Nanopart. Res. 15, 1415-1421 (2013). doi:10.1007/s11051-012-1415-2

6. P. Saini, V. Choudhary, B.P. Singh, R.B. Mathur, S.K. Dhawan, Polyaniline-MWCNT nanocomposites for microwave absorption and EMI shielding. Mater. Chem. Phys. 113(3), 919-926 (2009). doi:10.1016/j.matchemphys.2008.08.065

7. Z. Wang, L. Wu, J. Zhou, B. Shen, Z. Jiang, Enhanced microwave absorption of $\mathrm{Fe}_{3} \mathrm{O}_{4}$ nanocrystals after heterogeneously growing with $\mathrm{ZnO}$ nanoshell. RSC Adv. 3(10), 3309-3315 (2013). doi:10.1039/c2ra23404a

8. B. Zhang, Y. Du, P. Zhang, H. Zhao, L. Kang, X. Han, P. Xu, Microwave absorption enhancement of $\mathrm{Fe}_{3} \mathrm{O}_{4}$ /polyaniline core/ shell hybrid microspheres with controlled shell thickness. J. Appl. Polym. Sci. 130(3), 1909-1916 (2013). doi:10.1002/app.39332 
9. X. Yan, D.S. Xue, Fabrication and microwave absorption properties of $\mathrm{Fe}_{0.64} \mathrm{Ni}_{0.36}-\mathrm{NiFe}_{2} \mathrm{O}_{4}$ nanocomposite. Nano-Micro Lett. 4(3), 176-179 (2012). doi:10.1007/BF03353710

10. P. Saini, V. Choudhary, B.P. Singh, R.B. Mathur, S.K. Dhawan, Enhanced microwave absorption behavior of polyaniline-CNT/ polystyrene blend in $12.4-18.0 \mathrm{GHz}$ range. Synth. Met. 161(16), 1522-1526 (2011). doi:10.1016/j.synthmet.2011.04.033

11. P. Saini, M. Arora, G. Gupta, B.K. Gupta, V.N. Singh, V. Choudhary, High permittivity polyaniline-barium titanate nanocomposites with excellent electromagnetic interference shielding response. Nanoscale 5(10), 4330-4346 (2013). doi:10. 1039/c3nr00634d

12. Q.Y. He, S.X. Wu, Z.Y. Yin, H. Zhang, Graphene-based electronic sensors. Chem. Sci. 3, 1764-1772 (2012). doi:10.1039/ c2sc20205k

13. Z. Yang, R.G. Gao, N.T. Hu, J. Chai, Y.W. Cheng, L.Y. Zhang, H. Wei, E.S.W. Kong, Y.F. Zhang, The prospective two-dimensional graphene nanosheets: preparation, functionalization, and applications. Nano-Micro Lett. 4(1), 1-9 (2012). doi:10.1007/ BF03353684

14. P. Russo, A. Hu, G. Compagnini, Sythesis, properties and potential applications of porous graphene: a review. Nano-Micro Lett. 5(4), 260-273 (2013). doi:10.5101/nml.v5i4

15. P. Saini, V. Choudhary, S.K. Dhawan, Improved microwave absorption and electrostatic charge dissipation efficiencies of conducting polymer grafted fabrics prepared via in situ polymerization. Polym. Adv. Technol. 23(3), 343-349 (2012). doi:10. 1002/pat.1873

16. J.T. Zhang, X.S. Zhao, Conducting polymers directly coated on reduced graphene oxide sheets as high-performance supercapacitor electrodes. J. Phys. Chem. C 116(9), 5420-5426 (2012). doi:10.1021/jp211474e

17. X.L. Dong, X.F. Zhang, H. Huang, F. Zuo, Enhanced microwave absorption in $\mathrm{Ni} /$ polyaniline nanocomposites by dual dielectric relaxations. Appl. Phys. Lett. 92(1), 013127 (2008). doi:10.1063/ 1.2830995

18. P. Saini, V. Choudhary, N. Vijayan, R.K. Kotnala, P. Saini, V. Choudhary, N. Vijayan, R.K. Kotnala, Improved electromagnetic interference shielding response of poly(aniline)-coated fabrics containing dielectric and magnetic nanoparticles. J. Phys. Chem. C 116(24), 13403-13412 (2012). doi:10.1021/jp302131w

19. Y.J. Yang, L.N. Zhang, S.B. Li, Z.M. Wang, J.H. Xu, W.Y. Yang, Y.D. Jiang, Vapor phase polymerization deposition conducting polymer nanocomposites on porous dielectric surface as high performance electrode materials. Nano-Micro Lett. 5(1), 40-46 (2013). doi:10.1007/BF03353730

20. X.W. Ni, X.J. Hu, S.Y. Zhou, C.H. Sun, X.X. Bai, P. Chen, Synthesis and microwave absorbing properties of poly(3,4ethylenedioxythiophene)(PEDOT) microspheres. Polym. Adv. Technol. 22(5), 532-537 (2011). doi:10.1002/pat.1676

21. H.L. Yu, T.S. Wang, B. Wen, M.M. Lu, Z. Xu et al., Graphene/ polyaniline nanorod arrays: synthesis and excellent electromagnetic absorption properties. J. Mater. Chem. 22, 21679-21685 (2012). doi:10.1039/c2jm34273a

22. P.B. Liu, Y. Huang, Decoration of reduced graphene oxide with polyaniline film and their enhanced microwave absorption properties. J. Polym. Res. 21, 430-434 (2014). doi:10.1007/ s10965-014-0430-7

23. W.C. Zhou, X.J. Hu, X.X. Bai, S.Y. Zhou, C.H. Sun, J. Yan, P. Chen, Synthesis and electromagnetic, microwave absorbing properties of core-shell $\mathrm{Fe}_{3} \mathrm{O}_{4}$-poly(3, 4-ethylenedioxythiophene) microspheres. ACS Appl. Mater. Interface 3(10), 3839-3845 (2011). doi:10.1021/am2004812

24. W.S. Hummers, R.E. Offeman, Preparation of graphitic oxide. JACS 80(6), 1339 (1958). doi:10.1021/ja01539a017

25. Y.F. Xu, Y. Wang, J.J. Liang, Y. Huang, Y.F. Ma, X.J. Wan, A hybrid material of graphene and poly (3,4-ethyldioxythiophene) with high conductivity, flexibility, and transparency. Nano Res. 2(4), 343-348 (2009). doi:10.1007/s12274-009-9032-9

26. A. Schaarschmidt, A.A. Farah, A. Aby, A.S. Helmy, Influence of nonadiabatic annealing on the morphology and molecular structure of PEDOT-PSS films. J. Phys. Chem. B 113(28), 9352-9355 (2009). doi:10.1021/jp904147v

27. S.A. Spanninga, D.C. Martin, Z. Chen, X-ray photoelectron spectroscopy study of counterion incorporation in poly (3, 4-ethylenedioxythiophene). J. Phys. Chem. C 113(14), 5585-5592 (2009). doi:10.1021/jp811282f

28. M. Oyharçabal, T. Olinga, M.P. Foulc, S. Lacomme, E. Gontier, $\mathrm{V}$. Vigneras, Influence of the morphology of polyaniline on the microwave absorption properties of epoxy polyaniline composites. Compos. Sci. Technol. 74, 107-112 (2013). doi:10.1016/j. compscitech.2012.10.016 